\title{
Comparative cytogenetic study in Muscidae flies
}

\author{
Parise-Maltempi, PP. ${ }^{\mathrm{a}}$ and Avancini, RMP. ${ }^{\mathrm{b}}$ \\ ${ }^{a}$ Departamento de Biologia, Instituto de Biociências, Universidade Estadual Paulista - UNESP, \\ Av. 24A, 1515, CEP 13506-900, Rio Claro, SP, Brazil \\ 'Organogenesis Inc., Canton, Massachusetts, USA \\ *e-mail: parise@rc.unesp.br \\ Received February 9, 2007 - Accepted April 7, 2006 - Distributed December 1, 2007
}

(With 2 figures)

\begin{abstract}
The chromosome modal number in Muscoidea Diptera is $2 \mathrm{n}=12$, including five pairs of autosomes and one sex chromosome pair. Nevertheless, some species with $2 \mathrm{n}=10$ chromosomes have been described, all of them from the Muscidae family. We analyzed the karyotype of some Muscidae species from different subfamilies and compared the obtained data with the karyotypes of some species of the families Calliphoridae and Sarcophagidae. Comparisons of these species with other Muscidae species revealed a considerable variation among their sex chromosomes. This variation in the length of the sex chromosomes suggests that parts of these chromosomes were lost or fused with autosomes. The constitutive heterochromatic regions and the nucleolar organizer regions (NORs) were also analyzed and some aspects about the relationship between these regions and the sex chromosomes are discussed.
\end{abstract}

Keywords: Muscidae, cytogenetics, sex chromosomes, heterochromatin, FISH.

\section{Estudo citogenético comparativo em moscas da família Muscidae}

\section{Resumo}

O número modal de cromossomos dos Dípteros Muscóideos é $2 \mathrm{n}=12$, incluindo cinco pares de autossomos e um par de cromossomos sexuais. No entanto, algumas espécies com $2 n=10$ cromossomos já foram descritas, sendo todas pertencentes à família Muscidae. No presente trabalho, foram analisados os cariótipos de algumas espécies de Muscidae de diferentes subfamílias e os dados obtidos foram comparados com os cariótipos de algumas espécies das famílias Calliphoridae e Sarcophagidae. Comparações destas espécies com outras da família Muscidae revelaram uma considerável variação entre seus cromossomos sexuais. Esta variação no tamanho dos cromossomos sexuais sugere que parte destes cromossomos foram perdidos ou sofreram fusão com autossomos. As regiões de heterocromatina constitutiva e as regiões organizadoras de nucléolos (RONs) foram também analisadas e alguns aspectos sobre a relação destas com os cromossomos sexuais são discutidos.

Palavras-chave: Muscidae, citogenética, cromossomos sexuais, heterocromatina, FISH.

\section{Introduction}

Several Muscidae species present economic and/or sanitary importance. The horn fly, Haematobia irritans (Linnaeus, 1758) is a common, hematophagous, obligate ectoparasite of cattle in Europe, North America and, more recently, in South America (Williams et al., 1985; Valério and Guimarães, 1983). The housefly, Musca domestica (Linnaeus, 1758), is widespread, breeds in a variety of organic matters, including human and animal excrement, and is a significant nuisance to human populations. Muscina stabulans (Fallén, 1817) is also widespread throughout the world, and is usually associated with waste products of livestock and agricultural processes (Williams et al., 1985). M. domestica and M. stabulans may be involved in the transmission of various pathogenic organisms to humans and animals. Ophyra chalcogaster (Wiedemann, 1830) is a Neotropical species found near poultry facilities and its larvae are facultative predators on the larvae of other flies, including the housefly. Synthesiomyia nudiseta (Van der Wulp, 1883) is a cosmopolitan species which breeds in several animals and vegetable materials, and shows a high degree of synanthropy in Brazil (Linhares, 1981).

The usual karyotype number in Cyclorrapha Diptera species is $2 n=12$, although some species, all of them from the Muscidae family, have $2 \mathrm{n}=10$. Among the latter species, Muscina stabulans and Haematobia irritans were studied by Avancini and Weinzierl (1994), Parise (1994), and Parise et al. (1996). These studies indicated 
that the absent chromosomes represent a heteromorphic pair, usually considered to be the sex chromosomes. The occurrence of $2 \mathrm{n}=10$ species in different Muscidae subfamilies probably reflects independent losses of sex chromosomes in different groups rather than a common origin for these species (Boyes, 1967).

In order to address the understanding of the sex chromosome origin and evolution in Diptera, we analyzed the chromosomes of three species of Muscidae and compared the results with previous data (Avancini and Weinzierl, 1994; Parise et al., 1996). Since in insects the NORs and heterochromatin can be associated with sex chromosomes, we also investigated these regions through FISH and $\mathrm{C}$ banding to identify the NORs and the constitutive heterochromatin localization, respectively.

\section{Material and Methods}

\subsection{Fly rearing}

The colonies of the species used in this work were constituted by individuals collected in different places. Ophyra chalcogaster and Synthesiomyia nudiseta were collected at the Campus of the State University of Campinas (São Paulo State, Brazil), and Musca domestica was collected at Sumaré city (São Paulo State, Brazil). The flies were maintained at the Laboratory of Entomology of the Department of Parasitology, State University of Campinas. The adults had access to cane sugar and water 24 hours/day, and were maintained at $24 \pm 2{ }^{\circ} \mathrm{C}, 40-50 \%$ relative humidity, and on a 12 hours light-dark cycle. The flies were fed with ground beef in order to stimulate the follicle development and egg production (except $M$. domestica).

\subsection{Chromosome analysis}

Mitotic chromosomes were obtained from the brains of L3 larvae. Meiotic chromosomes were obtained from the testicular cells of young males. Hypotonic treatment and fixation were done as described by Imai et al. (1988). Mean descriptive values of the karyotype were calculated using the information obtained from a minimum of one well spread mitotic metaphase plate from each of 5-10 individuals. The nomenclature used to describe the chromosome morphology was based on Levan et al. (1964). The C-banding was performed using Sumner's technique (1972), with slight modifications to allow the localization of constitutive heterochromatic regions, and fluorescent in situ hybridization (FISH) was performed in mitotic and/or meiotic cells using a rDNA probe $(\mathrm{pDm} 238$ : recombinant plasmid with a $11,5 \mathrm{~kb}$ fragment corresponding to the rDNA repetitive unit of D. melanogaster, inserted in the Eco RI site of the pBR 322 plasmid (Roiha et al., 1981)). The FISH procedure was done as described in Parise-Maltempi and Avancini (2000). The slides were examined using an Olympus ${ }^{\circledR}$ fluorescence microscope and photographs were taken on 400 ASA color negative films.

\section{Results}

\subsection{Ophyra chalcogaster (subfamily Azeliinae)}

The sampled individuals of $O$. chalcogaster has six pairs of chromosomes, with three pairs of metacentric chromosomes (II, V and the sex chromosomes), and three pairs of submetacentric chromosomes (I, III, and IV). Pair IV has an arm ratio very close to the limit between metacentric and submetacentric chromosomes, and was classified as submetacentric (Figure 1a, and Tables 1 and 2). Pair I has a secondary constriction in the short arm (Figure 1b). The sex chromosomes form a very small metacentric pair in which the $X$ is approximately 3.5 times smaller than the chromosome I, the largest chromosome of the whole complement. All the autosomes have small blocks of heterochromatin in the pericentromeric region (Figure 1c), and the sex chromosomes are totally heterochromatic (Figure 1d). There is an interstitial band on the short arm of pair II which is coincident to a positive $\mathrm{C}$ band region (Figure 1d).

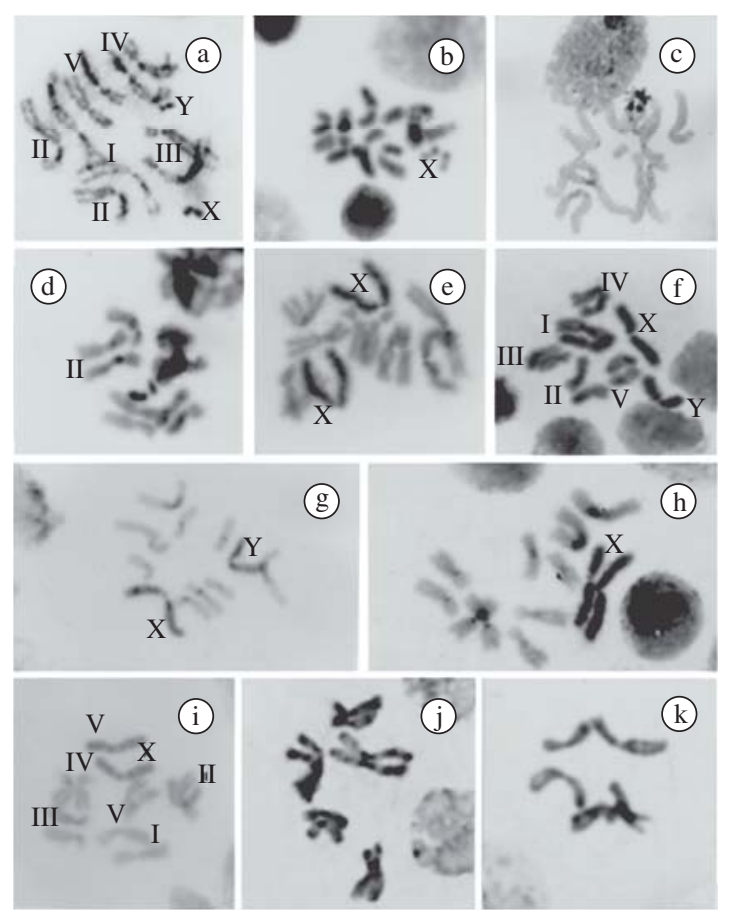

Figure 1. Mitotic chromosomes of Muscoidea flies. a) male metaphase of $O$. chalcogaster; b) female metaphase of $O$. chalcogaster; c, d) C-banded chromosomes of $O$. chalcogaster - note in figure $\mathrm{d}$ an interstitial band in pair II; e, f) chromosomes of $S$. nudiseta after conventional staining; g, h) C-banded chromosomes of S. nudiseta - sex chromosomes are totally heterochromatic and the autosomes present pericentromeric bands; i) C-banded chromosomes of M. domestica; j) C band in M. stabulans; and k) H. irritans mitotic complement. In $\mathrm{j}$ and $\mathrm{k}$ : five chromosome pairs in each species. The heteromorphic pair is absent. 
Table 1. Total and relative lengths of the chromosomes of several Muscidae species. The relative length of the Y chromosome was expressed as a function of the $\mathrm{X}$ length.

\begin{tabular}{lcccccccc}
\hline \multicolumn{1}{c}{ Species } & I & II & III & IV & V & X & Y & TCL $(\mu \mathbf{m})$ \\
\hline O. chalcogaster & 8.3 & 7.3 & 6.6 & 6.4 & 5.7 & 2.7 & 1.7 & 37 \\
M. domestica & 7.1 & 6.4 & 5.8 & 5.0 & 4.6 & 6.6 & n.a. & 35.5 \\
S. nudiseta & 7.2 & 4.9 & 4.4 & 4.0 & 3.5 & 8.7 & 6.6 & 32.7 \\
M. stabulans* & 7.4 & 6.4 & 5.6 & 5.2 & 4.9 & - & - & 29.5 \\
H. irritans $^{*}$ & 6.7 & 6.0 & 5.5 & 5.1 & 4.3 & - & - & 27.6 \\
\hline
\end{tabular}

*The karyotypes of these species were studied by Parise (1994), Parise et al. (1996), and Avancini and Weinzierl (1994). TCL: total complement length; n.a.: not available

Table 2. Chromosome arm ratios of several Muscidae species.

\begin{tabular}{lccccccc}
\hline \multicolumn{1}{c}{ Species } & I & II & III & IV & V & X & Y \\
\hline O. chalcogaster & $1.9(\mathrm{Sb})$ & $1.4(\mathrm{M})$ & $2.8(\mathrm{Sb})$ & $1.7(\mathrm{Sb})$ & $1.4(\mathrm{M})$ & $1.5(\mathrm{M})$ & $1.3(\mathrm{M})$ \\
M. domestica & $1.3(\mathrm{M})$ & $1.4(\mathrm{M})$ & $1.7(\mathrm{Sb})$ & $1.7(\mathrm{Sb})$ & $1.4(\mathrm{M})$ & $1.6(\mathrm{M})$ & n.a. \\
S. nudiseta & $1.1(\mathrm{M})$ & $1.2(\mathrm{M})$ & $2.0(\mathrm{Sb})$ & $1.4(\mathrm{M})$ & $1.3(\mathrm{M})$ & $1.4(\mathrm{M})$ & $1.2(\mathrm{M})$ \\
M. stabulans $^{*}$ & $1.1(\mathrm{M})$ & $1.1(\mathrm{M})$ & $1.5(\mathrm{M})$ & $1.7(\mathrm{Sb})$ & $1.3(\mathrm{M})$ & - & - \\
H. .rritans $^{*}$ & $1.3(\mathrm{M})$ & $1.1(\mathrm{M})$ & $2.3(\mathrm{Sb})$ & $2.0(\mathrm{Sb})$ & $1.6(\mathrm{M})$ & - & - \\
\hline
\end{tabular}

*The karyotypes of these species were studied by Parise (1994), Parise et al. (1996), and Avancini and Weinzierl (1994).

M: metacentric; Sb: submetacentric; n.a.: not available

\subsection{Synthesiomyia nudiseta (subfamily Reinwardtiinae)}

The species $S$. nudiseta also has six pairs of chromosomes, with five autosomes and a sex chromosome pair $(\mathrm{XX} / \mathrm{XY}$ ) (Figures 1e,f). The karyotype is illustrated in Figure $1 \mathrm{f}$ and the data for the complement are shown in Tables 1 and 2. Pairs I, II, IV, and V are metacentric, and pair III is submetacentric. The $\mathrm{X}$ is the largest chromosome of the complement and together with the $\mathrm{Y}$ forms a metacentric heterologous pair. The $\mathrm{C}$ banding of mitotic chromosomes shows constitutive heterochromatin in the pericentromeric region of all the autosomes (Figures $1 \mathrm{~g}, \mathrm{~h}$ ). The sex chromosomes are totally heterochromatic as observed by the positive heteropicnose under Giemsa staining and by $\mathrm{C}$ banding (Figures 1e,h).

\subsection{Musca domestica (subfamily Muscinae)}

As reported by Milani et al. (1967) and El Agose et al. (1992), the analyzed population of $M$. domestica also has six pairs of chromosomes (Figure 1i). Morphometric analyses revealed two pairs of submetacentric (III and IV) and three pairs of metacentric autosomes (I, II and $\mathrm{V}$ ). The $\mathrm{X}$ chromosome is also metacentric (Tables 1 and 2). No heteromorphic chromosomes were visualized in 36 individuals examined. The C-banding pattern was similar to that found by El Agose et al. (1992) and Hediger et al. (1998) in which all the autosomes have pericentromeric $\mathrm{C}$ bands and the $\mathrm{X}$ chromosome is totally heterochromatic, although darker staining is seen in its pericentromeric region (Figure 1i).

\subsection{In situ hybridization}

In situ hybridization with an rDNA probe showed that the NORs are located on autosomal pairs in the ana- lyzed Muscidae species. There is an intense signal in pair II of M. stabulans (Figure 2a), which is coincident to the location of the secondary constriction and a large block of heterochromatin (Figure 1j). In M. domestica, the hybridization signal is located in pair II (Figure 2b), and in S. nudiseta the signal is on pair III (Figure 2c).

\section{Discussion}

Most Muscidae species have six pairs of chromosomes and one of these represents the heteromorphic pair (Boyes et al., 1964). Our results generally agree with these authors, except for M. stabulans (Reinwardtiinae) (Parise et al., 1996) and H. irritans (Muscinae) (Avancini and Weinzierl, 1994; Parise, 1994), which have five chromosome pairs, without the heteromorphic pair. In addition to M. stabulans, Boyes et al. (1964) found other exceptions with five chromosome pairs, including Phaonia variegata (Phaoniinae) and Neomyia nudissima (Muscinae).

Kaul and Tewari (1979) studied seven species of the family Muscidae. Four of these are representatives of the subfamily Phaoniinae and have $2 \mathrm{n}=10$, while the remaining three species have $2 n=12$. However, the complement of these species did not resemble those of other $2 \mathrm{n}=10$ species since they have four metacentric chromosome pairs of medium to very large size and a pair of small dot-like chromosomes. The dot-like chromosomes could be the sex pair because they did not show somatic pairing.

The data obtained here were compared with our early results (Avancini and Weinzierl, 1994; Parise et al., 1996). The karyotype of the species with 10 chro- 

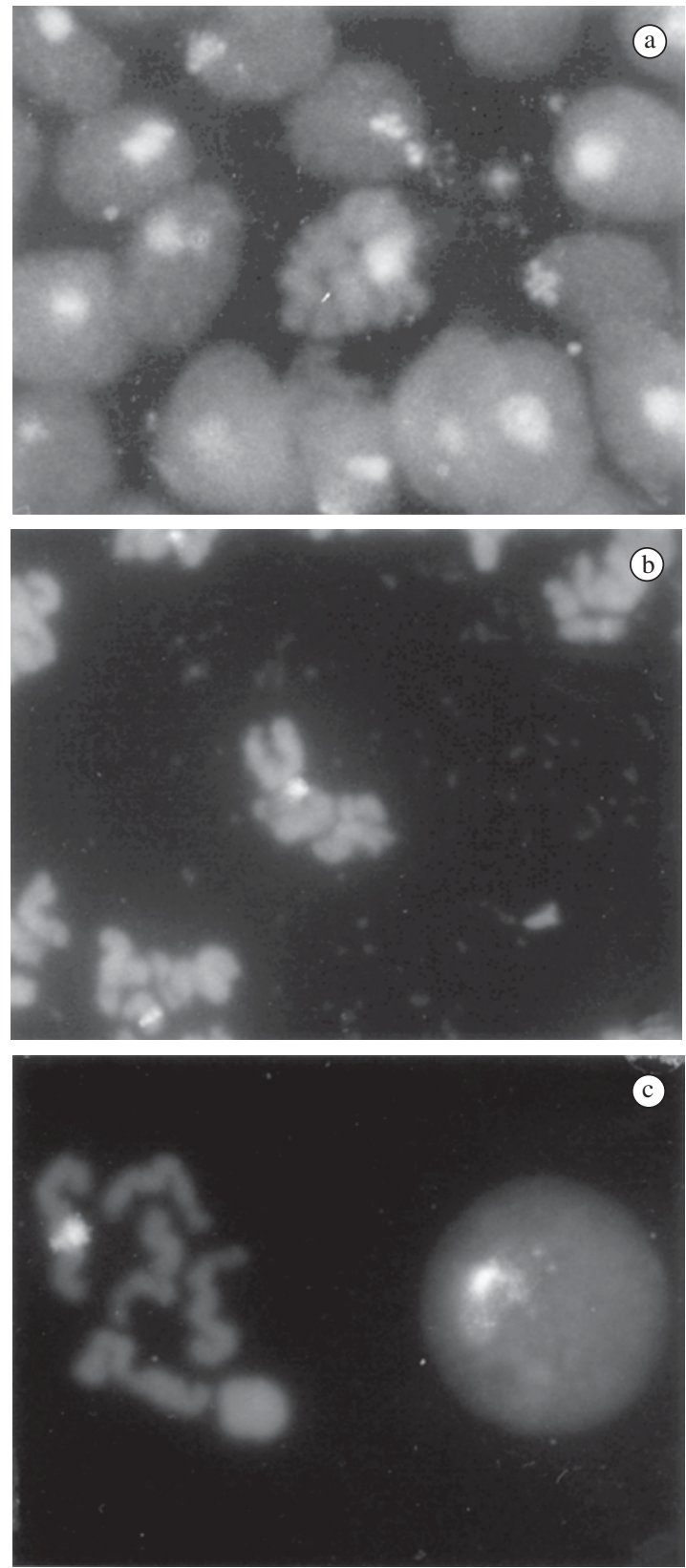

Figure 2. FISH using a Drosophila rDNA probe detected with biotin and counterstained with propidium iodode. a) M. stabulans (mitotic chromosomes); b) S. nudiseta (meiotic chromosomes); and c) M. domestica (meiotic chromosomes). Figures $2 \mathrm{a}$ and 2c: NORs located in pair II, and Figure 2b: NORs located in pair III.

mosomes differed from each other in some aspects. In $H$. irritans, pairs III and IV are submetacentric, while in M. stabulans only pair IV is submetacentric. In addition, M. stabulans has two secondary constrictions in pair I and another in pair II, whereas $H$. irritans has only one secondary constriction located in pair II. Variations in the arm ratios and location of secondary constrictions in the species with $2 \mathrm{n}=10$ were also noted by Boyes et al. (1964). Such differences were considered sufficient to indicate that the species were not closely related.

The five species showed little variation in the size of their autosomes. In M. domestica, M. stabulans, and $H$. irritans, these chromosomes are slightly larger than in $S$. nudiseta, whereas $O$. chalcogaster has much larger autosomes than the other species. The autosomal morphology also varied little among the species. Except for $O$. chalcogaster, pair I is typically metacentric. Pairs II and $\mathrm{V}$ are metacentric in all species. In M. stabulans pair III is metacentric while in the other species it is submetacentric. Pair IV is metacentric in $S$. nudiseta but submetacentric in the other species.

The sex chromosomes, identified in some of the analyzed species, are metacentric but varied considerably in size. O. chalcogaster, that presents the largest autosomes, has very small sex chromosomes. In $S$. nudisseta, these chromosomes are very large, and the $\mathrm{X}$ chromosome represents the largest of the complement. In M. domestica the sex chromosomes are of medium size.

Comparing the results about five Muscidae species analysed in our research, is possible observed that the total chromosome length was very similar in four (M. stabulans, H. irritans, M.domestica, and $S$. nudiseta), excluding the $\mathrm{X}$ chromosomes of $M$. domestica and $S$. nudiseta. This observation indicates that the absence of sex chromosomes makes the genomes of $M$. stabulans and $H$. irritans smaller than of flies where the $\mathrm{X}$ chromosome is present. There was no evidence of a possible fusion of the sex chromosomes to autosomes in these two species.

Variations in the morphology of the sex chromosomes in the subfamily Muscinae have also been reported (Boyes et al., 1964). Thus, the Y chromosome of Musca vetustissima is exceptionally large and submetacentric, the $\mathrm{Y}$ of $M$. domestica calleva is relatively small, and metacentric, and this sex chromosome of $M$. autumnalis is tiny and acrocentric. These authors described a similar situation in the subfamily Phaoniinae, where Phaonia basalis (Zetterstedt, 1838) has a very large sex pair, Ophyra leucostoma (Wiedemann, 1830) has tiny sex chromosomes, and Muscina stabulans and Phaonia variegata (Meigen, 1826) lack the sex pair that is normally present in the 12 chromosomes of several species.

Similar variations to those described above were also observed in the present study, suggesting that substantial changes in these chromosomes can be tolerated, without serious consequences to most species in these subfamilies. The fact that most of these species have sex chromosomes, regardless of their size, indicates that the presence of sex chromosomes represents the more primitive condition in Muscidae. The reduction of the chromosome number appears to have occurred independently in the different genera of the two subfamilies (Muscinae and Reinwardtiinae). If one accepts the hypothesis of the loss of sex chromosomes in Muscidae, the evolution of these chromosomes from homomorphic sex chromo- 
somes must be considered (Ohno, 1967; for review see Bull, 1983 and John, 1988). Thus, the absence of sex chromosomes could represent a new stage after the differentiation of these chromosomes.

The quantity and localization of constitutive heterochromatin have a significant role in the sex chromosome evolution. The incorporation of heterochromatin represents an initial step in the specialization of these chromosomes (John, 1988; reviewed by Jablonka and Lamb, 1990). Schmid (1983) has argued that heterochromatinization precedes morphological differentiation of the sex chromosomes. This initial step is believed to isolate a chromosomal segment containing one or more major sex determining genes from recombination (Ohno, 1967).

Most dipteran species have heterochromatin, which can extend from pericentromeric regions to include whole arms of some chromosomes or even the entire sex chromosomes (Kaul et al., 1978; Wallace and Newton, 1987; Marchi and Mezzanotte, 1990; Bedo, 1991; El Agose et al., 1992). While in many species only the $Y$ chromosome is heterochromatic, in the examined species both sex chromosomes were totally heterochromatic. The large darkly stained heterochromatic blocks in the sex chromosomes are probably not involved in sex determination and the genes related with sex determination in the analyzed Diptera Muscoidea are probably located in an autosome. Some animals, like $M$. domestica, carry sex chromosomes that lack large blocks of heterochromatin but are viable. This indicates that these missing C-banding positive parts contain no vital genes (Hediger et al., 1998).

Boyes and Van Brink (1965) reported a tendency for the $\mathrm{X}$ chromosome (and to a lesser extent the $\mathrm{Y}$ ) to accumulate heterochromatin and to increase in size in several subfamilies of calyptrate Diptera. These authors believed that in some Muscidae subfamilies the large $\mathrm{X}$ and $\mathrm{Y}$ chromosomes had been completely and independently lost.

The NORs are also good markers for evolutionary studies since the rDNA genes are extremely well conserved amongst Diptera species. In most Diptera, the NOR(s) are located in the sex chromosomes (Bedo and Howells, 1987; Bedo and Webb, 1989; Willhoeft and Franz, 1996; Willhoeft, 1997). In the present study, the NORs were located in autosomes and not in the sex chromosomes of M. stabulans, $M$. domestica, and $S$. nudiseta. This situation may represent an intermediate step in the chromosomal evolution in this group. Some genome sequences, including the major ribosomal genes, may have moved from the sex chromosomes to autosomes, in order to avoid damage due to a partial loss of the sex chromosomes.

In general, certain cytogenetically important regions always occurred on Muscoidea chromosomes II and III. Thus, M. stabulans and H. irritans, for example, have a secondary constriction in the short arm of chromosome II where there is also an interstitial $\mathrm{C}$ band. The NOR is located in this same region in M. stabulans.
O. chalcogaster has a C band in pair II and another in pair III. In S. nudisseta the NORs are located in pair III, and in M. domestica in pair II. Chromosomes II and III may be associated with sex determination, as has been reported in some Diptera species. These observations strongly suggest, but do not prove, an autosomal sex determination in Muscidae species. Despite of the important publications on Drosophila, M. domestica, and other species, the origin of the sex chromosomes of flies had remained largely non-documented.

Acknowledgments - The authors thank Dr. Recco-Pimentel SM. (Department of Cell Biology, UNICAMP) for the use of the fluorescence photomicroscope and some of her laboratory facilities, Dr. Prado AD. (Department of Parasitology, UNICAMP) for his valuable information on the taxonomy and distribution of Muscidae, Dr. Botella LM. (Centro de Investigaciones Biológicas, Madrid, Spain) for supplying the pDm probe, and Dr Martins C. (Department of Morphology, UNESP, Botucatu) for critically reading the manuscript. Parise-Maltempi PP. was supported by a Ph.D. fellowship from CAPES.

\section{References}

AVANCINI, RMP. and WEINZIERL, RA., 1994. Karyotype of the Horn fly, Haematobia irritans (L.) (Diptera, Muscidae). Cytologia, vol. 59, p. 269-272.

BEDO, DG., 1991. Cytological characterization of heterochromatin in mitotic and meiotic chromosomes of the Old World screwworm fly, Chrysomya bezziana (Diptera: Calliphoridae). Genome, vol. 34, p. 631-637.

BEDO, DG. and HOWELLS, AT., 1987. Chromosomal localization of the white gene of Lucilia cuprina (Diptera: Calliphoridae) by in situ hybridization. Genome, vol. 29, p. $72-75$.

BEDO, DG. and WEBB, GC., 1989. Conservation of nucleolar structure in polytene tissues of Ceratitis capitata (Diptera: Tephritidae). Chromosoma, vol. 98, no. 6, p. 443-449.

BOYES, JW., 1967. The cytology of muscoid flies. In WRIGHT, JW. and PAL, RWHO. (eds.), Genetics of insect vectors of diseases. Elsevier Publ. Co, Amsterdam, p. 371-384.

BOYES, JW., COREY, MJ. and PATERSON, HE., 1964. Somatic chromosomes of higher Diptera. IX. Karyotypes of some muscid species. Can. J. Zoolog., vol. 42, no. 6, p. 1025-1036.

BOYES, JW. and Van BRINK, JM., 1965. Chromosomes of Calyptrate Diptera. Can. J. Genet. Cytol., vol. 7, no. 4, p. $537-550$

BULL, JJ., 1983. Evolution of sex determining mechanisms. The Benjamim-Cummings Publishing Company, California.

EL AGOSE, M., LEMEUNIER, F. and PERIQUET, G., 1992. Mitotic and salivary gland chromosome analyses in the Musca domestica L. (house fly) (Diptera: Muscidae). Heredity, vol. 69, p. 57-64.

HEDIGER, M., NIESSEN, M., MULLER-NAVIA, J., NOTHIGER, R. and DUBERDORFER, A., 1998. Distribution of heterochromatin on the mitotic chromosomes of Musca domestica L. in relation to the activity of male-determining factors. Chromosoma, vol. 107, no. 4, p. 267-271. 
IMAI, HT., TAKAHATA, N., MARUYANA, T., DANIEL, A., HONDA, T., MATSUDA, Y. and MOTIWARI, K., 1988 Theoretical bases for karyotype evolution. II. The fusion burst in man and mouse. Jpn. J. Genet., vol. 63, no. 4, p. 313-342.

JABLONKA, E. and LAMB, MJ., 1990. The evolution of heteromorphic sex chromosomes. Biology Review, vol. 65, no. 3, p. 249-276.

JOHN, B., 1988. The biology of heterochromatin. In VERMA, RS. (ed.). Heterochromatin: Molecular and Structural Aspects. Cambridge University Press, Cambridge, p. 1-147.

KAUl, D., CHATURVEDI, R., GAUR, P. and TEWARI, RR., 1978. Cytogenetics of the genus Parasarcophaga (Sarcophagidae: Diptera). Chromosoma, vol. 68, no. 1, p. 73-82.

KAUL, D. and TEWARI RR., 1979. The chromosomes of Passeromyia heterochaeta Villeneuve (Muscidae: Diptera). Experientia, vol. 35, no. 9, p. 1155-1156.

LEVAN, A., FREDGA, K. and SANDBERG, AA., 1964. Nomenclature for centromeric position on chromosomes. Hereditas, vol. 52, no. 2, p. 201-220.

LINHARES, AX., 1981. Synantropy of Muscidae, Faniidae and Anthomyiidae (Diptera) in the city of Campinas, São Paulo, Brazil. Rev. Bras. Entomol., vol. 35, p. 231-243.

MARCHI, A. and MEZZANOTTE, R., 1990. Inter and intraspecific heterochromatin variation detected by restriction endonuclease digestion in two sibling species of the Anopheles maculipennis complex. Heredity, vol. 65, p. 135-142.

MILANI, R., RUBINI, PG. and FRANCO, MG., 1967. Sex determination in the housefly. Genetica Agraria, vol. 21, p. 385-411.

OHNO, S., 1967. Sex chromosomes and sex-linked genes. Springer-Verlag, Berlin.

PARISE, PP., 1994. Estudo citogenético de duas espécies de dípteros de interesse médico-veterinário: Haematobia irritans e Muscina stabulans (Diptera, Muscidae). (Master thesis) Universidade Estadual de Campinas, UNICAMP, Brazil.
PARISE, PP., AVANCINI, RMP. and RECCO-PIMENTEL, SM., 1996. Karyotypic characterization of Muscina stabulans (Fallen) (Diptera: Muscidae) using conventional staining, silver staining and C-banding. Caryologia, vol. 49, no. 1, p. 13-20.

PARISE-MALTEMPI, PP. and AVANCINI, RMP., 2000. Cytogenetics of the Neotropical Fleshfly Pattonella intermutans (Diptera, Sarcophagidae). Genet. Mol. Biol., vol. 23, no. 3, p. 563-567.

ROIHA, H., MILLER, JR., WOODS, L.C. and GLOVER, DM., 1981. Arrangements and rearrangements of sequences flanking the two types of rDNA insertion in D. melanogaster. Nature vol. 290 p. 749-754.

SCHMID, M., 1983. Evolution of sex chromosomes and heterogametic systems in Amphibia. Differentiation, vol. 23, p. 13-22.

SUMNER, AT., 1972. A simple technique for demonstrating centromeric heterochromatin. Exp. Cell Res., vol. 75, no. 1, p. 304-306.

VALÉRIO, JR. and GUIMARÃES, JH., 1983. Sobre a ocorrência de uma nova praga, Haematobia irritans (L.) (Diptera, Muscidae) no Brasil. Rev. Bras. Zool., vol. 1, no. 4, p. 417-8.

WALLACE, A. and NEWTON, ME., 1987. Heterochromatin diversity and cyclic responses to selective silver staining Aedes aegypti (L.). Chromosoma, vol. 95, no. 1, p. 89-93.

WILLHOEFT, U., 1997. Fluorescence in situ hybridization of ribosomal DNA to mitotic chromosomes of tsetse flies (Diptera: Glossinidae: Glossina). Chromosome Res., vol. 5, no. 3, p. 262-267.

WILLHOEFT, U. and FRANZ, G., 1996. Identification of the sex-determining regions of the Ceratitis capitata $Y$ chromosome by deletion mapping. Genetics, vol. 144, no. 2, p. 739-745.

WILLIAMS JD., SUTHERST, RW., MAYMALD, GF. and PETERBRIDGE, CP., 1985. The Southward spread of buffalo fly (Haematobia irritans) in eastern Australia and its survival through a severe winter. Aust. Vet. J., vol. 62, no. 11, p. 367-369. 